\title{
Does Forward Guidance Matter in Small Open Economies? Examples from Europe
}

\author{
Jakub Rybacki** \\ \$Collegium of Economic Analysis, SGH Warsaw School of Economics
}

Submitted: September 15, 2018 • Accepted: January 21, 2019

\begin{abstract}
The effect of forward guidance on interest rate expectations in small, open economies is often described as heterogeneous. There are examples when financial markets adjusted term structure to reflect interest rate forecasts provided in the projections published by the central banks. On the other hand, medium-term expectations can persistently deviate from trajectories presented by decision-makers, influenced by foreign monetary policy. Our aim is to find the maximal forecast horizon where the domestic forward guidance of local banks in European economies affects market interest rate expectations strongly as compared to the ECB policy. We analyzed the term structure of interest rates in Sweden, Norway, and the Czech Republic. Central banks in these three economies provide the most mature forward guidance, e.g., regularly publishing interest rate forecasts with detailed discussions. The three-month interbank rate path calculated with the Nelson-Siegel model was contrasted with both the trajectory of policy rates presented in central bank projections and that implied by the three-month EURIBOR. We found that interest rate expectations were more influenced by ECB policy than by domestic assumptions when the forecast horizon exceeds four quarters.
\end{abstract}

JEL classification: E52, E58

Keywords: forward guidance, interest rate projections, Nelson-Siegel model, DieboldMariano test

\footnotetext{
${ }^{*}$ Corresponding Author. Email: jr70663@sgh.waw.pl
} 


\section{Introduction}

In the aftermath of the subprime crisis, major central banks were forced to stimulate the economy with unconventional policies after achieving an effective lower bound on interest rates. In order to lower yields on financial instruments with longer duration (e.g. Treasury Bonds), policymakers responded with greater transparency in communicating their assumptions about the term structure of interest rates to market participants. Despite solid theoretical support (e.g., Eggertsson and Woodford, 2003), the effects of the new tools were mixed (Swanson, 2017).

The subject literature describes a problem termed the forward guidance puzzle (Giannoni et al., 2015). The introduction of forward guidance policy was accompanied by high confidence of monetary authorities e.g. in the United States or the Eurozone. Theoretical dynamic stochastic general equilibrium (DSGE) models overestimated the response of the output gap and inflation related to interest rate expectations shocks. This class of models predicts rapid expansion of activity, when interest rate expectations are anchored below the natural rate level.

Empirical evidence showed neither the full adjustment of markets interest rate expectations to the levels declared by the monetary authorities nor strong macroeconomic feedback. Policymakers' declarations of no policy change in the two-year horizon failed to lower yields on instruments with a duration greater than five years (Swanson, 2017). Communication policies has only modest positive effects on long-term interest rate. Introduction of the forward guidance by Fed lowered sensitivity of rate expectations to economic surprises and market volatility (e.g., Raskin, 2013).

The problem of managing expectations is much more complex in small, open economies. Central banks are required to account for real exchange rates in their reaction function (Ball, 1999). They cannot anchor interest rate expectations at a lower or higher level than the leading bank in the region without consequences for foreign exchange rates. In order to lower long term interest rates, monetary authorities need to convince the markets that the currency should systematically depreciate.

Our hypothesis states that market expectations regarding exchange rates and interest rates are not that flexible. Therefore, the term structure should adapt only to short-term central bank commitments (e.g., in the horizon up to one year) and not to long-term ones. Market expectations about interest rates in the longer horizon should, rather, converge toward the expected rates set by the central banks of the leading economies in a region.

Our goal is to find if there exists some common horizon in three European economies, when expectations about ECB policy become predominant over domestic forward guidance in navigating market expectations about future short-term interest rates (e.g., after six quarters or two years). The research outcome should help design communication policies for the central 
banks, which so far have not applied forward guidance and do not provide regular information about policymakers' expectations (i.e., with publication of a monetary policy report). The outcome of this analysis is important as credible forward guidance is expected to lower the cost of money by exhausting the risk premia related to uncertainty about policymakers' future decisions (e.g., Campbell et al., 2012).

We conducted our investigation based on market expectations regarding developments of three-month interbank rates in three European economies: Norway, Sweden, and the Czech Republic. Central banks in these selected countries provide the most mature forward guidance worldwide. Their inflation reports are published least frequently on a quarterly basis and contain forecasts with fan chart projections and detailed discussions about changes in the projections.

We analyzed market expectations regarding central bank policies using the following methodology. Implied future interest rates were derived from the market interest rate swap curve using the Nelson-Siegel model (Diebold and Li, 2006). The actual increases or decreases in these future interest rates were contrasted with changes in the policy rates in the local central bank projections and with changes in the three-month interbank rate expectations in the Eurozone (also calculated using the Nelson-Siegel approach).

We found limited impact of domestic forward guidance on market expectations based on the entire period considered in the research (2007-2018). The conclusion changes after 2012, when financial market started to play greater attention to central banks' communication. We found that Eurozone monetary policy played a superior role for horizons of six quarters or more, whereas domestic forward guidance played a superior role only in the short horizon (less than four quarters).

This paper is structured as follows. The next section reviews the literature analyzing the effectiveness of forward guidance in a small, open economy. Section 2 briefly discusses interest rate forecasts published by the central banks in Europe. Section 3 presents the research methodology. Section 4 describes the results of the analysis. Section 5 concludes the paper.

\section{Literature Review}

In this section, we present findings of research on forward guidance in small economies. The expected benefit from implementing this new communication policy is, due to greater transparency, the exhaustion of the risk premia related to uncertainty about rate policy. But even on the theoretical front, there is no accepted consensus on the optimal scope of monetary policy transparency in an open economy. The optimal communication policy should, to the greatest extent, help execute the statutory mandate of central banks, e.g., by anchoring 
inflation expectations at the targeted level.

The literature does not provide evidence that the publishing of interest rate forecasts by the central banks improves the predictability of monetary policy, e.g., inflation, interest rates, etc., for market participants (Rudebusch and Williams, 2008). Furthermore, the policy could have negative consequences: the major risks include miscommunication (i.e., treating commitment as unconditional by public opinion) and overconfidence in the central bank forecasts relative to other sources of information.

The empirical literature describes the effect of forward guidance on market rates in small economies as heterogeneous. Svensson (2015) described experiences of Sweden and New Zealand. This author pointed out that market expectations converged directly to the Swedish Riksbank projections during the phase of lowering the policy rate in 2009. Yet, in the period 2011-2012, the Swedish central bank frequently failed to push market expectations. Markets did not believe in the rapid tightening of monetary conditions announced by the Riksbank's executive board. The experiences of the Reserve Bank of New Zealand (RBNZ) were less discouraging, although its projections sometimes misled the markets regarding the scale of interest rate changes, i.e., central bank behavior was different than stated in the previous projection, despite no significant macroeconomic surprises.

Quantitative event studies confirm that publishing new projections drives market expectations. However, these studies also report significant problems with convergence of the term structure to the trajectory expected by monetary authorities. Brubakk et al. (2017) employed the Gürkaynak et al. (2005, further termed as GSS) framework to identify the effects of publishing new interest rate projections in Sweden. The proposed method decomposed monetary policy shocks into surprises related to the present level of policy rates and expectations about their future trajectory. The authors presented evidence that shifts in the policy path expected by the executive board are positively correlated with changes in market expectations, yet major moves typically occur prior to the publication of a new report.

In their study of New Zealand, Detmers and Nautz (2012) provided evidence that interest rate projections only have a significant impact on short-term market rates. Based on a method similar to GSS, the authors also highlighted the weakening effect of forward guidance during the global financial crisis when major rate moves actually occurred. Interestingly, Detmers and Nautz concluded that shortening rate projections to one year would be the most desirable policy because the long-term projections were more likely to destabilize, rather than pinpoint, expectations.

Other studies reflect the failures of forward guidance to affect market consensus forecasts. There is strong evidence that forward guidance fails to improve the predictability of interest rates. Kool and Thornton (2015) reported no change in the unconditional forecast error of the market consensus median after the introduction of forward guidance in Sweden and Norway 
(with New Zealand as an exception). The performance of predictions in these countries was not different from the random walk process. Furthermore, economies where central banks do not communicate their future policies achieved similar forecast errors for short-term interest rates. These findings were confirmed by Jain and Sutherland (2018), who also highlighted no reduction in disagreement between forecasters on their projections of the future interest rate path. The single benefit of communicating future expected policy rates was a lower frequency of interest rates forecasts revisions, compared to the period prior to introducing forward guidance (Winkelmann, 2016).

The literature provides a solid description of the forward guidance effects on consensus forecasts and the yields curve. On the other hand, the economic research seems to be silent on the impact of foreign policy spillovers on the effectiveness of local forward guidance, even though it is clear that international monetary policy spillovers affect the behavior of local banks in small, open economies (e.g., Gajewski et al., 2018). Therefore, it seems reasonable to analyze how the monetary policies of leading central banks in the region influence the effectiveness of local forward guidance. Before introducing the methodology of our research, we will briefly discuss the content of the inflation reports in selected economies.

\section{A Brief History of Forward Guidance in Small Economies}

This section summarizes the data used in this research and presents a brief history of the publishing of policy rate projections in inflation reports by central banks worldwide. The concept of expectations management with forward guidance through interest rate projections became popular in the academic literature after the U.S. Federal Reserve introduced dot-plot charts of future policy rates and expressed the macroeconomic conditions required to increase interest rates in 2012. A dot-plot is a chart reflecting interest rate forecasts for the next three years and the long run as provided by each individual Federal Open Market Committee's (FOMC) member. It remains one of the policy tools used today.

However, the history of navigating financial market expectations through projection rates published by central banks goes back much further. In 1997, the RBNZ introduced the market interest rate as one of the projected variables it publishes on a quarterly basis. At the beginning, the bank presented forecasts for the 90-day interbank rate. Then it forecasted the official cash rate (OCR) directly set by monetary authorities. Despite the long history of forward guidance in New Zealand, we decided not to analyze the RBNZ case, as its policy is affected by the decisions of three central banks (U.S. Federal Reserve, Reserve Bank of Australia, and People's Bank of China). Accounting for all three foreign central banks would 
significantly complicate our analysis.

Our paper is focused on Europe and interactions with the European Central Bank (ECB). Amongst central banks in this region, Norges Bank was the first to start publishing its forecasts, which it did in 2005. The first releases contained projections of annual indicators. The project achieved maturity in 2009 when a fan chart with quarterly forecasts was introduced. The key policy rate in this economy describes the interest rate on banks' reserves up to a specified quota. The projection contains forecasts for approximately the next three-year window-i.e., the next 12 to 16 quarters, depending on the publication period.

The idea of publishing policy rate forecasts has swiftly found followers. In 2007, policy rate projections were introduced by the Sveriges Riksbank and the Bank of Israel (BoI). From the beginning, Swedish authorities have been publishing detailed fan charts with quarterly forecasts of average policy rates in a given quarter. The Swedish policy rate defines the cost of borrowing or depositing funds at the Riksbank for a period of seven days. Forecasts for the next 12 to14 quarters are presented.

The policy of the BoI is less transparent. Even today, the BoI provides only annual indicators. The bank's macroeconomic forecast report contains fan charts with quarterly indicators (including bank rate), yet the data are not publicly available. For this reason, from among the above-mentioned central banks, only the Scandinavian ones are deeply scrutinized in this paper. The strong motivation for our policy analysis of the two Scandinavian economies also comes from their deep interlinkages with the Eurozone.

Finally, the Czech National Bank (CNB) has been publishing projected market and policy rates since 2008 (the sole country in Central Europe to do so). Similar to the RBNZ approach, the first projections were dedicated to interbank interest rates (initially PRIBOR1Y, then PRIBOR3M). The bank started publishing forecasts for two-week repo rates directly set by monetary authorities (presented as a quarterly average) in 2013. The CNB publishes a decomposition of factors affecting interest rate projections, including expert judgments. The projection window of the CNB is much shorter than that of the Scandinavian central banks. The trajectory for the next 7 to 10 quarters is forecasted.

Our aim is to examine whether expectations of the future policy rate path derived from the interbank rates of the STIBOR, NIBOR, and PRIBOR (up to 12-months) and swap rates in those economies (longer tenors) are converging closer to the trajectories forecasted by the national central banks, rather than to the shape of the Eurozone yield curve expected by markets. We use changes in swap rates to measure market reactions to monetary policy shocks because those instruments do not contain a substantial credit risk premium (only interest, no capital is transferred) or accrued interest related to coupon payments. Therefore, interest rate swap prices should more accurately reflect the perception of interest rate risk. 


\section{Methodology}

The aim of this section is to present the methodology of our research. Our goal is to analyze whether the expected change in short-term interest rates in a small economy (derived from the current yield curve) is better predicted by the national central bank's forward guidance or by a similarly defined shift in expectations regarding ECB policy.

The first step in our analysis was to approximate the yield curve with the standard Nelson-Siegel (NS) formula for daily data readings. Realized interest rates were transformed to logarithmic form. We used the following equation to represent the NS model (Diebold and $\mathrm{Li}, 2006)$ :

$$
R_{t}(m)=\beta_{1, t}+\beta_{2, t} \cdot\left(\frac{1-e^{-\varphi_{t} \cdot m}}{\varphi_{t} \cdot m}\right)+\beta_{3, t} \cdot\left(\frac{1-e^{-\varphi_{t} \cdot m}}{\varphi_{t} \cdot m}-e^{-\varphi_{t} \cdot m}\right)
$$

where $R_{t}$ denotes the interbank interest rate or the swap rate for a term of $m$ months at time $t$. $\beta_{1, t}, \beta_{2, t}$, and $\beta_{3, t}$ are the weights of the three estimated latent dynamic factors. The decay parameter $\left(\varphi_{t}\right)$ was set to 0.0609 , in line with recommendations in the literature (Diebold and Li, 2006). The beta parameters were estimated using the ordinary least squares method.

Our aim was to use estimated parameters in an event study. We focused on observations directly following the publication of inflation and/or monetary policy reports by the three central banks of interest (Riksbank, Norges Bank, and Czech National Bank). For example, if the monetary policy report was published by one of these central banks on December 15 , we used interest rate data for December 16 (the next trading day). We assume that after one day the financial markets should be able to price in all information from interest rate projections and at the same time, the risk that market participants' expectations would be changed by other events (e.g., economic surprises) is minimized. Calculations were conducted independently for each central bank.

Based on the yield curve estimates, we computed bootstrapped three-month interbank forward rates for the next $h$ months ( $h=3,6,9$ etc.) to mimic market expectations of future policy paths. ${ }^{1}$ We decided to use the three-month tenor as it is the most commonly forecasted by private entities, as well as being used in the surveys of professional forecasters provided by various central banks. Furthermore, it mostly prices expectations related only to the outcome of the most recent Monetary Policy Council (MPC) or executive board meetings. In recent

\footnotetext{
${ }^{1}$ The term bootstrapping in this paper refers to the financial meaning of this word, i.e., implying current expectations about interest rates in the future, using the information about term structure. Bootstrapping also has a different statistical meaning describing inference based on randomly selected subsamples. Such analyses, however, were not carried out as part of this work.
} 
years, central banks in developed economies have preferred to use a gradual approach during policy tightening, linking important decisions with publications of monetary policy reports (usually provided on a quarterly basis). Using longer (e.g., two-year) tenors would require us to decompose changes in interest rates into two factors: the effect directly dedicated to MPC decisions in the forecast horizon, and the effects of changes in the yield curve after subsequent meetings. We used the following formula to bootstrap forward interest rates expected at time $t$ (Rubaszek, 2016):

$$
R_{t, 3 m}{ }^{f}(h)=\frac{(3+h) \cdot R_{t}(3+h)-h \cdot R_{t}(h)}{h} .
$$

$R_{t, 3 m}{ }^{f}(h)$ is a bootstrapped three-month forward rate computed for the period $h$ months after time $t$ (i.e., the day directly following the publication of an inflation report). $R_{t}(m)$ is the current $m$-month short-term rate implied by the NS model (based on parameters estimated with equation 1). For example, to compute the three-month rate one quarter after the December 15, 2016 publication of the monetary policy report, we would need to input the spot six-month rate $R_{t=2016 / 12 / 16}(3+3)$ and the spot three-month rate $R_{t=2016 / 12 / 16}(3)$ into equation (2).

The central banks' inflation projections typically provide forecasts of an average policy rate or a short-term interbank rate in the next quarters. To provide a consistent estimate of market expectations, we set the forecast horizon $h$ to the middle of the quarter corresponding to the central bank projections. For example, when a central bank provides a policy rate projection for the first quarter of the year, the horizon date $h$ is set to be February 15; for the second quarter, $h$ equals May 15, etc.

We used the following formula to calculate the expected change in the three-month market interest rate between the horizon date $h$ and the day $t$ following publication of the inflation report:

$$
\Delta R_{t, 3 m}^{f}(h)=R_{t, 3 m}^{f}(h)-R_{t, 3 m}^{f}(0) .
$$

Calculations presented in formulas (1), (2), and (3) were also repeated for the Eurozone three-month EURIBOR to derive expected changes between the period $t+h$ and $t$. All calculations were done for the periods when central banks published monetary policy reports in these tree economies (Sweden, Norway, and the Czech Republic). We also calculated the shift in the local central bank projections, $\Delta R_{t, 3 m, \text { projection }}{ }^{f}(h)$, using formula (3).

We directly compare changes in the money market rate in small, open economies with changes in the policy rate in the respective central bank projections and with similarly de- 
fined changes in the Eurozone interbank rates. Calculations are described by the following equations:

$$
\begin{aligned}
& e_{1, t}(h)=\Delta R_{t, 3 m, \text { interbank }}^{f}(h)-\Delta R_{t, 3 m, \text { projection }}{ }^{f}(h) \\
& e_{2, t}(h)=\Delta R_{t, 3 \text { m,interbank }}^{f}(h)-\Delta R_{t, 3 m, \text { ECBrates }}^{f}(h)^{\prime}
\end{aligned}
$$

where $\Delta R_{t, 3 \text { m,interbank }}{ }^{f}(h)$ denotes the expected change in the three-month interbank rate in the small economy $h$ months on from time $t . \Delta R_{t, 3 m, \text { projection }}{ }^{f}(h)$ describes the shift in a policy rate (or an interbank rate if applicable) in the central bank projections. Finally, the $\Delta R_{t, 3 m, E C \text { Brates }^{f}}(h)$ is the expected change in the bootstrapped three-month EURIBOR, based on a similarly defined NS model $h$ months on from time $t$.

In order to verify which trajectory has a greater impact on rate expectations, we calculate root mean squared error statistics (i.e., RMSE) and the results of the two-sided and one-sided Diebold-Mariano (DM) tests (Diebold and Mariano, 1995; Harvey et al., 1997). The RMSE formulas are given as follows:

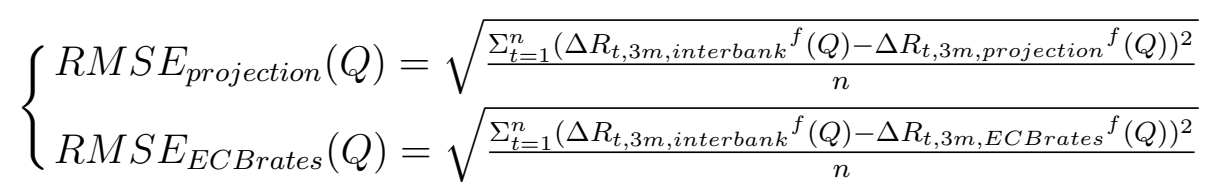

where the numerator contains one of the error series calculated using formula (4) and $n$ is the number of observations in the available sample. To highlight our interest in quarterly forecasts, we used index $Q$ instead of $h$.

We define $Q 1$ as the period following the quarter when the inflation report containing forward guidance was published, $Q 2$ as the next quarter afterward, and so on. For example, if the document was published in February, the middle day of the second quarter of the year (April-June) will be denoted as $Q 1$, and the middle day of the third quarter (July-September) as $Q 2$. Based on prediction errors, we calculated the DM test statistics.

The basic DM test assumes calculation of differentials between two error series. We use symmetrical squared-error loss transformations. The differential $(d)$ formula is presented in equation (6):

$$
d=g\left(e_{1 t}\right)-g\left(e_{2 t}\right), \quad g\left(e_{i t}\right)=e_{i t}^{2}
$$

The null hypothesis states that the expected value of the differential is zero, implying a similar accuracy of forecasts. We provide results of both one-sided and two-sided tests. The 
alternative hypothesis for the one-sided test particularly points out which forecast is better (either domestic central bank projection or term structure describing market expectations regarding ECB policy). In the case of two-sided test alternative test states only that the predictive accuracy between these two sources is different. Test statistics were computed with the Harvey et al. (1997) correction for small samples. The formula is given as follows:

$$
\mathrm{HLNDM}=\sqrt{\frac{T+1-2 h+h \cdot(h-1)}{T}} \cdot \frac{d}{V(d)}
$$

where $T$ denotes sample size, $h$ the forecast horizon, and $V(d)$ is an estimate of variance related to the differential $d$. The HLNDM statistic has a normal distribution under the null hypothesis, implying equal precision of forecasts.

\section{Estimation Results}

In this section, we present the expected changes in short-term interest rates derived with the methodology described above. We also calculate root mean squared error statistics (RMSE) from predictions regarding interest rate changes $Q$ quarters ahead for each central bank as well as DM test statistics.

Calculations were performed on two different samples: 1) the full sample with all available quarterly observations (starting from 2007 in Sweden, 2009 in Norway, and 2008 in the Czech Republic), and 2) the subsample of quarterly observations starting from late 2012-the date corresponding to the introduction of the dot-plot by the U.S. Federal Reserve and the publication of the pioneering article written by Campbell et al. (2012) highlighting the importance of navigating markets through transparent communication of future rates. Although these two events did not explicitly change the behavior of central banks in Scandinavia or the Czech Republic, we argue that market attention to published forecasts has increased as this type of communication has become widespread amongst central banks. Therefore, we expect the projections become more relevant to the investors' decisions from 2012 onward. Both samples end in May 2018.

\section{Sweden}

The first country analyzed is Sweden. The expected change in the three-month STIBOR through time (11 quarters), the corresponding change in policy rate in the Riksbank projections, and the corresponding expected change in the EURIBOR 3M are presented in Figure 1. The largest changes in interest rate levels, which also imply a greater volatility, occur in cases of instruments with longer maturity. The standard deviation of expectations increases with 
the forecast horizon and becomes greatest at the longest Q11 horizon. Therefore, sensitivity of interest rate changes does not differ from patterns reported by Gürkaynak et al. (2005); there is no visible volatility reduction as reported, for example, by Raskin (2013) for the U.S. economy.

There are three significant episodes in the discussed period (2007-2018). First, the Riksbank projections successfully managed expectations during the financial crisis of 2008-2009, although the forward guidance to a great extent mirrored the behavior of the Eurozone yield curve over that time frame. Second, the central bank failed to convince the markets in late 2011 and 2012 that financial tightening of monetary policy was likely to occur in the twoyear horizon. Market expectations in Sweden have most likely adapted to those observed in the Eurozone. Finally, during 2015 and 2016, the Swedish market expected a steeper yield curve than given by the Riksbank projections, again following expectations about the Eurozone policy. Shift in expectation did not occur, despite the central bank using large scale asset purchases (LSAP). Thus, the use of other unconventional instruments did not trimmed expectations for rate hikes.

Based on the RMSE statistics, the change in the policy rate derived from the Riksbank projections turned out to be a less accurate predictor of Sweden's interbank rate term structure than changes in the Eurozone yield curve for every forecast horizon. We interpret this as evidence that expectations about local interest rates tend to converge to market assumptions regarding changes in global monetary policy. Especially in the medium term (more than one year), coordination between central banks' decisions is expected (see, e.g., Taylor (2013)). The results of the RMSE calculations are presented in Figure 2 and in Table 1.

Underperformance of Riksbank rate projections in relation to Eurozone market expectations is visible in both selected samples. However, the RMSE statistics were significantly lower from 2012 onward as interest rate volatility diminished, compared with the period directly following the Lehman Brothers collapse (2008-2010). In 2008 and 2009, the Riksbank initially projected further rate hikes, then benign cuts. Instead, much greater policy easing was delivered.

The results of the DM test confirm that the Riksbank's interest rate projections in general provided less accurate guidance for local interest rates than the expectations regarding the EURIBOR increase (Table 2). Statistically significant outcomes are visible in the very short (up to two-quarter) and far (beyond two-year) horizons.

The results change for the period when major central banks put greater emphasis on communication. In the 2012-2018 period, the investigated projections have similar powers of steering local market interest rates for the first six-quarter horizons. For longer horizons, the rate expectations converge toward the path followed by the Eurozone interest rate swap curve. 


\section{Norway}

The next country analyzed is Norway. The expected change in the three-month NIBOR calculated with the NS model, the change in policy rate in the Norges Bank projection, and the corresponding change in the three-month EURIBOR are presented in Figure 3.

In contrast with Sweden, the greatest deviation of expectations in Norway occurs in the forecast horizon of seven to eight quarters. There were two major events worth mentioning: Lehman Brothers collapse and monetary easing during 2014-2016 periods.

The Norges Bank made a major communication mistake after the Lehman Brothers collapse: projections assumed tightening, while market expectations priced imminent rate cuts by $200 \mathrm{bp}$. Therefore, discrepancy between market participants and policymakers interest rates expectations reached the historically highest level.

Incorrect decisions of the central bank could result from the backward-looking approach to the major inflation index increase i.e. CPI-ATE. which describes consumer prices dynamics adjusted for tax changes and shifts in cost of energy products. In 2007 mentioned index overshoot both central bank target and $90 \%$ confidence interval of macroeconomic projections. Monetary authorities likely were afraid of an another surprise in a row. Norges Bank also underestimated the financial crisis effects.

For further information, please see the text boxes titled Evaluation of the projections for 2008 in Norges Bank (2009) and Changes in the interest rate path in Norges Bank (2008). We excluded observations from December 2008 from the RMSE calculations so as not to distort the final conclusions.

Finally, the Norges Bank tended to provide forecasts of a much flatter yield curve compared to the interbank expectations during the 2014-2016 period. However, the Norwegian central bank failed to convince the markets as stronger rate increases in the Eurozone were priced by bond investors.

Research on the Norges Bank policy revealed similar results to those from Sweden. Based on the RMSE statistics, Norway's central bank projections have a lower predictive accuracy than the ECB rate expectations after exceeding the six-quarter horizon in both time frames. Taking into account the period of 2009-2018, the Norges Bank projections seem to have systematically worse guidance compared with the Eurozone expected interest rate fluctuations over all the forecast horizons (Table 3, Figure 4a). This likely resulted from an overestimated tightening pace after communication mistakes prior to the Lehman Brothers collapse. The Norway central bank projected further rate hikes before the U.S. recession, but it instead delivered cuts afterward. On the other hand, during the more recent period (2012-2018), the Norges Bank projections outperformed ECB expectations in the short-term horizon (up to four quarters). The possible reason for the change is the increase in the importance of forecasts published by the central bank; however, the methodology used in this study does 
not allow us to answer this question.

As in the Swedish case, the DM tests for Norway indicate a similar accuracy when changes in the Norges Bank policy rate (in the projection) and the expectations regarding EURIBOR rates were compared in the full sample. The hypothesis of equal accuracy is not rejected at the $\alpha=0.05$ confidence level (Table 4 ).

Shortening the sample to the 2012-2018 period leads to the same conclusion for Norway as for Sweden. One-sided DM tests indicate a greater performance of domestic central bank projections in the two-quarter ahead horizon (yet at a higher confidence level, $\alpha=0.1$ ). On the other hand, market expectations regarding changes in the ECB policy perform better for horizons longer than six quarters. Both two-sided and one-sided tests reject the null hypothesis for Q8-Q11 forecast horizons.

\section{The Czech Republic (Czechia)}

Finally, we analyzed the case of the Czech Republic, qualified as a European emerging economy according to the MSCI or JP Morgan bond indices. The projections presented by the executive board of the Czech National Bank (CNB) have shorter horizons as compared to their Scandinavian peers. The balanced panel consists of forecasts for up to six quarters ahead.

The interest rate forecasts in the CNB projections are much more volatile compared to its Scandinavian peers. Similar to Norway, the Czech central bank projected more excessive tightening compared to financial market expectations after the 2008 financial crisis and an overly accommodative trajectory during the 2013-2015 period. Detailed information is provided in Figure 5.

Taking into account all the available history, the CNB projections generate larger errors than predictions derived from market interest rate swap instruments in the euro currency. The projection errors fell after 2012 (see Table 5, Figure 6). The central bank's forward

guidance outperforms the foreign policy impact in the first three-quarter window in the sample covering the period 2012-2018.

Similar to the cases of the Norges Bank and Riksbank, the DM test indicates that interest rate projection accuracy does not divert strongly from the ECB expectations after 2012. The p-value for the null hypothesis drops regularly with longer forecast horizons (for 6 quarters ahead it is equal to 0.09) when the alternative hypothesis states that the ECB interest rate changes are more accurate in predicting the changes of the local yield curve than the forward guidance. 


\section{Conclusions}

Based on the examples of Sweden, Norway, and the Czech Republic, we find very limited evidence that forward guidance in small and open economies persistently provides solid indication of expected changes in the market rate term structure. The investigation based on the shorter sample (2012-2018) suggests that the communication policy is effective in a horizon shorter than four quarters and neutral in the horizon of another additional two quarters. Commitments with a longer time horizon seem to be unproductive.

Expectations for longer tenors (above two years) are more likely to converge toward the shape of market rates in the Eurozone. This implies lower effectiveness of the expectation management policies used by the small open economy central banks compared to leading regional peers like the U.S. Federal Reserve or European Central Bank. In order to affect longterm interest rates (e.g., 10-year government bonds), central banks are required to mix the forward guidance policy with a strong impulse from alternative unconventional instruments, i.e., large-scale asset purchases. Implementation of such policies is subject to adverse economic risk resulting from distortion of market structure, e.g., an increased propensity to debt issuance by non-financial enterprises after introducing a corporate asset purchase program, and credit risk problems (see Klein, 2017).

Evidence from Norway, and to some extent from the Czech Republic, for the period 20122018 suggests the superior role of local monetary authorities only for short-term (less than one year) interest rates. This confirms the conclusions of Detmers and Nautz (2012) regarding the optimal duration of forward guidance (four quarters). In our results, the explanatory power of central bank projections was similar to the trajectory of predictions based on the euro yield curve in the forecast horizons up to six quarters ahead. Afterward, the latter factor played a superior role. The response of financial investors to central bank communications seems to be focused mainly on the prediction for forthcoming policy meetings (e.g., in the next six months).

Finally, the relevance of the central banks' forward guidance is likely to be different during periods of financial stress. We found that our test conclusions changed when managing interest rate expectations gained popularity in the major central banks (from 2012 onward). Test results provided no evidence of supremacy of the ECB policy when the samples were extended to the period directly following the Lehman Brothers collapse. This observation may imply a significant role for central banks in directing market expectations during turning points of business cycles (cf. the example of Sweden discussed by Svensson (2015)). Future policy events will surely provide more evidence to verify this hypothesis. 


\section{References}

Ball, L. M. (1999). Monetary policy rules, chapter Policy rules for open economies., pages 127-156. National Bureau of Economic Research, Inc.

Brubakk, L., ter Ellen, S., and Xu, H. (2017). Forward guidance through interest rate projections: does it work? Working Paper 2017/6, Norges Bank.

Campbell, J., Evans, C., Fisher, J., and Justiniano, A. (2012). Macroeconomic effects of Federal Reserve forward guidance. Working Paper Series WP-2012-03, Federal Reserve Bank of Chicago.

Detmers, G.-A. and Nautz, D. (2012). The Information Content of Central Bank Interest Rate Projections: Evidence from New Zealand. The Economic Record, 88(282):323-329.

Diebold, F. and Li, C. (2006). Forecasting the term structure of government bond yields. Journal of Econometrics, 130(2):337-364.

Diebold, F. and Mariano, R. (1995). Comparing Predictive Accuracy. Journal of Business and Economic Statistics, 13(3):253-63.

Eggertsson, G. and Woodford, M. (2003). Optimal Monetary Policy in a Liquidity Trap. NBER Working Papers 9968, National Bureau of Economic Research, Inc.

Gajewski, K., Jara, A., Kang, Y., Mok, J., Moreno, D., and Serwa, D. (2018). International spillovers of monetary policy: lessons from Chile, Korea, and Poland. NBP Working Papers 290, Narodowy Bank Polski, Economic Research Department.

Giannoni, M., Patterson, C., and Del Negro, M. (2015). The Forward Guidance Puzzle. 2015 Meeting Papers 1529, Society for Economic Dynamics.

Gürkaynak, R., Sack, B., and Swanson, E. (2005). Do Actions Speak Louder Than Words? The Response of Asset Prices to Monetary Policy Actions and Statements. International Journal of Central Banking, 1(1).

Harvey, D., Leybourne, S., and Newbold, P. (1997). Testing the equality of prediction mean squared errors. International Journal of Forecasting, 13(2):281-291.

Jain, M. and Sutherland, C. S. (2018). How Do Central Bank Projections and Forward Guidance Influence Private-Sector Forecasts? Staff working papers, Bank of Canada.

Klein, M. C. (2017). Just how much money did the ECB lose on its Steinhoff investment? Financial Times, December 6. 
Kool, C. and Thornton, D. (2015). How Effective Is Central Bank Forward Guidance? Review, 97(4):303-22.

Norges Bank (2008). Monetary Policy Report 3/2008.

Norges Bank (2009). Monetary Policy Report 1/2009.

Raskin, M. (2013). The effects of the Federal Reserve's date-based forward guidance. Finance and Economics Discussion Series 2013-37, Board of Governors of the Federal Reserve System (US).

Rubaszek, M. (2016). Forecasting the Yield Curve With Macroeconomic Variables. Econometric Research in Finance, 1(1):1-21.

Rudebusch, G. and Williams, J. (2008). Revealing the Secrets of the Temple: The Value of Publishing Central Bank Interest Rate Projections. In Asset Prices and Monetary Policy, pages 247-289. National Bureau of Economic Research, Inc.

Svensson, L. (2015). Day One Keynote Address: Forward Guidance. International Journal of Central Banking, 11(4):19-64.

Swanson, E. (2017). Measuring the Effects of Federal Reserve Forward Guidance and Asset Purchases on Financial Markets. NBER Working Papers 23311, National Bureau of Economic Research, Inc.

Taylor, J. (2013). International monetary policy coordination: past, present and future. BIS Working Papers 437, Bank for International Settlements.

Winkelmann, L. (2016). Forward guidance and the predictability of monetary policy: a wavelet-based jump detection approach. Journal of the Royal Statistical Society Series C, $65(2): 299-314$. 
Figure 1: Implied change in three-month STIBOR, three-month EURIBOR, and change of policy rate in the Riksbank projection

(1a) Change in three-month STIBOR rate implied by the Swedish swap curve (1 denotes 100 basis points[bp])

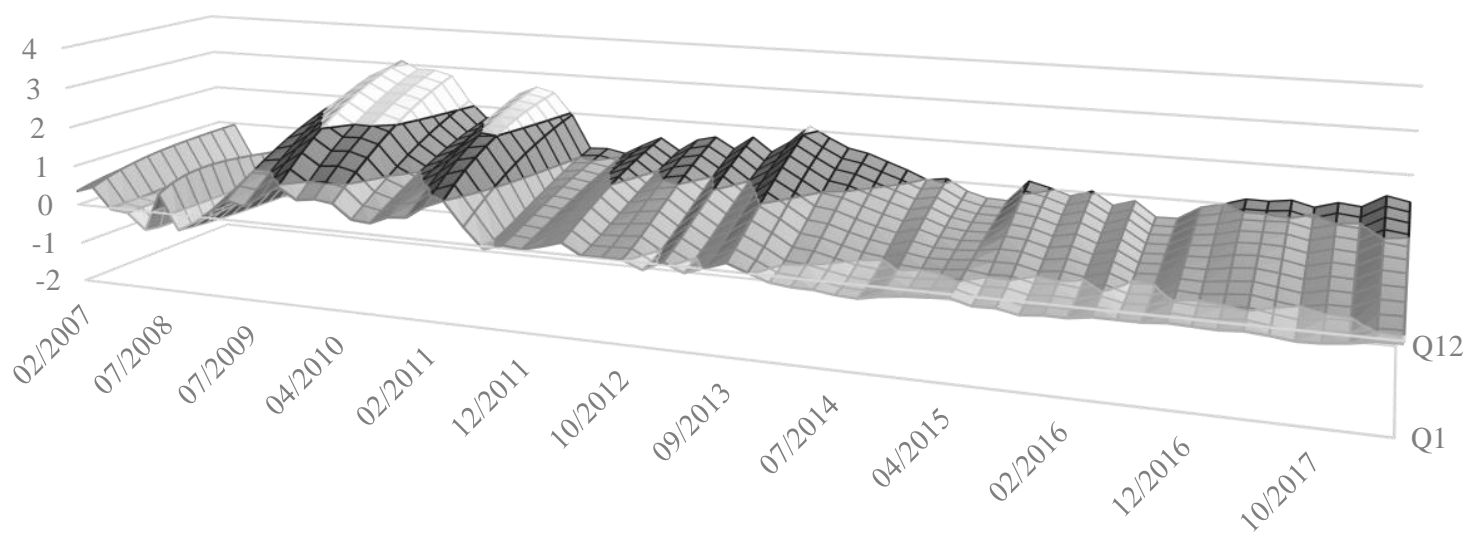

(1b) Change in policy rate in the Riksbank projections $(1=100 \mathrm{bp})$

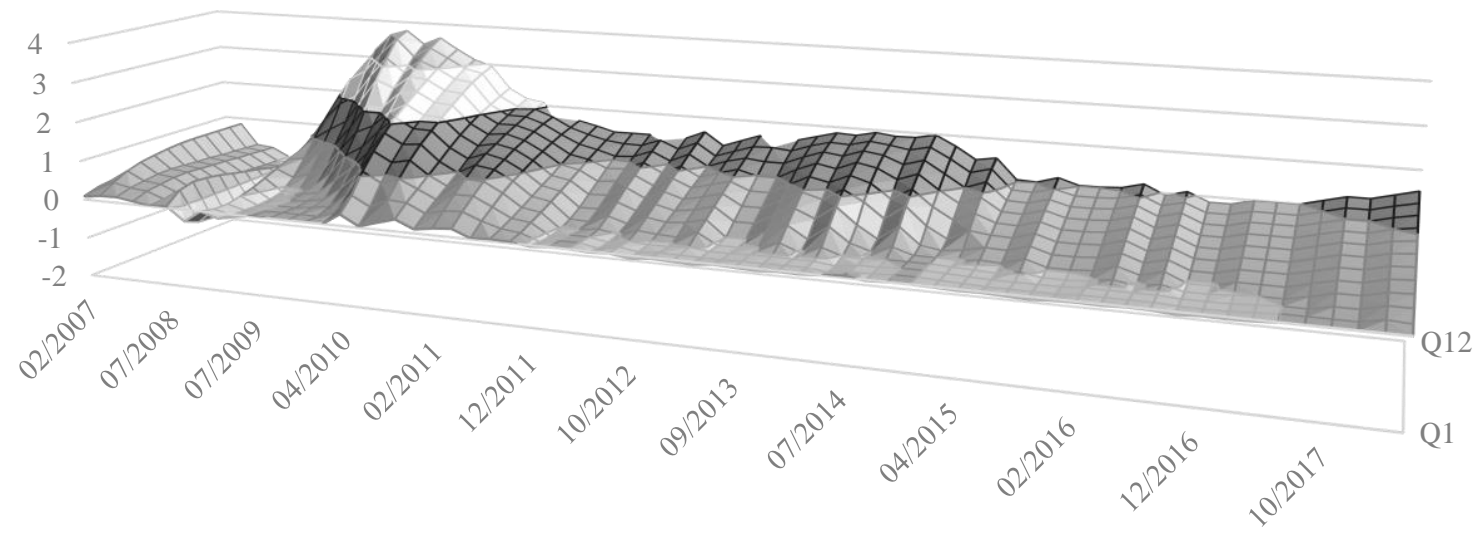

Continued on the next page 
Figure 1: Implied change in three-month STIBOR, three-month EURIBOR, and change of policy rate in the Riksbank projection (Continued)

(1c) Change in three-month EURIBOR rate implied by the Eurozone swap curve $(1=100 \mathrm{bp})$

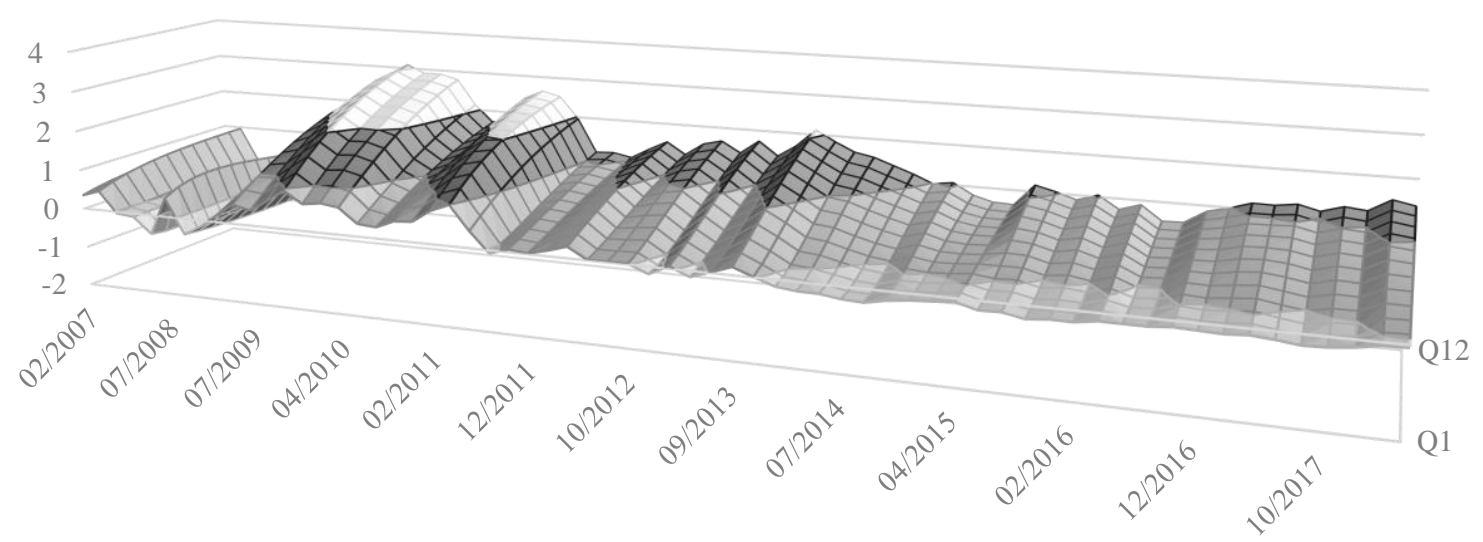

Source: Author's calculations.

Note: The chart presents the expected changes in interest rates in forthcoming quarters during the period of 2007-2018. The x-axis presents the timeframe. The y-axis presents the forecast horizon (Q1 = next quarter, Q12 = end of forecast horizon). Finally, the z-axis is the number of basis points by which interest rates are expected to increase or decrease. The aim of the graph is to visualize the similarity between market rate expectations in Sweden (panel 1) and the Riskbank projection (panel 2) or the expectations in the Eurozone (panel 3). The changes in the three-month market rates were calculated using the Nelson-Siegel model. See the methodology section for further information. The EURIBOR chart uses data corresponding to the monetary policy report publication dates. Its shape will be different for every central bank. 
Figure 2: Predictive accuracy of expected change in the STIBOR three-month ratecomparison between the central bank projection and the EURIBOR3M expectations

(a) RMSE (2007-2018)

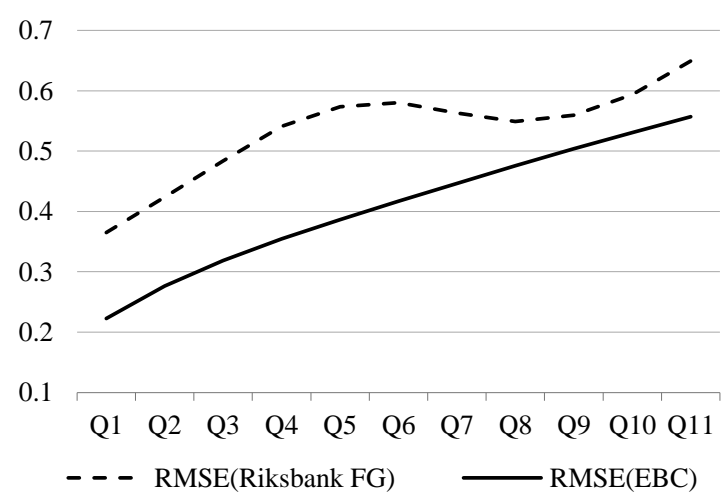

(b) RMSE (2012-2018)

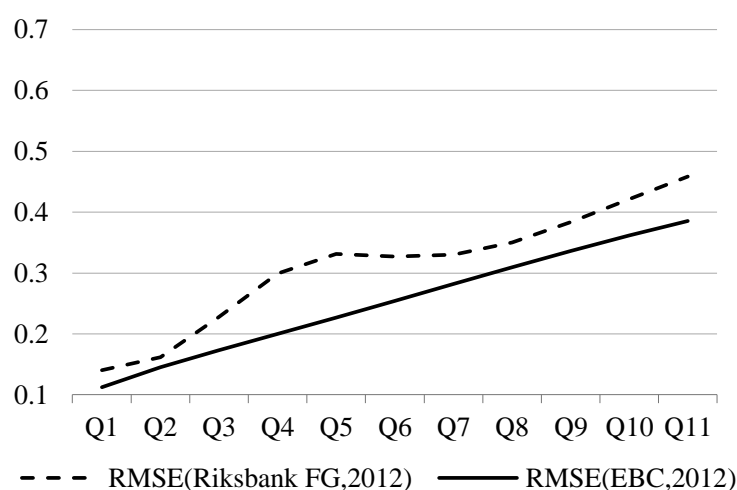

Source: Author's calculations.

Note: The dotted line denotes root mean square error statistics for central bank projections, calculated with formula (5). Error is defined as the difference between expected change in the three-month rate in Sweden and forecasted change in policy rate in the Riksbank projections. The solid line depicts similarly defined statistics, where error is defined as the difference between expected short-term rate increases in Sweden and the Eurozone (EURIBOR 3M). Q1, Q2, ... denote next forecast horizons; see the methodology section for further information.

Figure 3: Implied change in the three-month NIBOR, three-month EURIBOR, and change in policy rate in the Norges Bank projections

(3a) Change in the three-month NIBOR rate implied by the Norway swap curve (1 denotes 100 basis points [bp]).

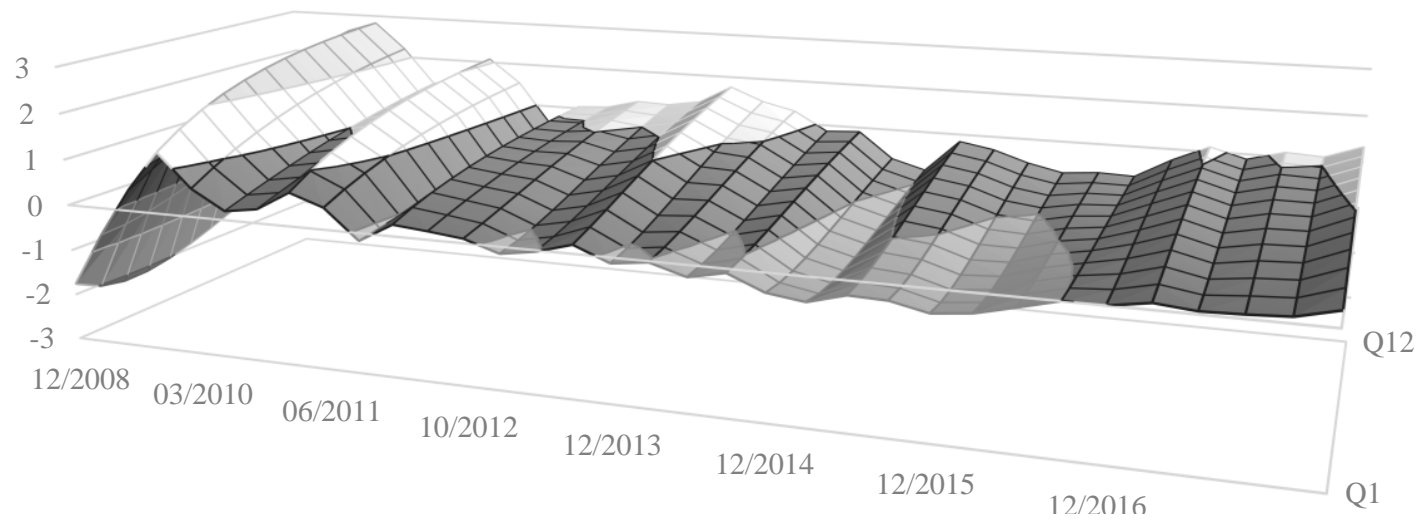

Continued on the next page 
Figure 3: Implied change in the three-month NIBOR, three-month EURIBOR, and change in policy rate in the Norges Bank projections (Continued)

(3b) Change in policy rate in the Norges Bank projection $(1=100 \mathrm{bp})$

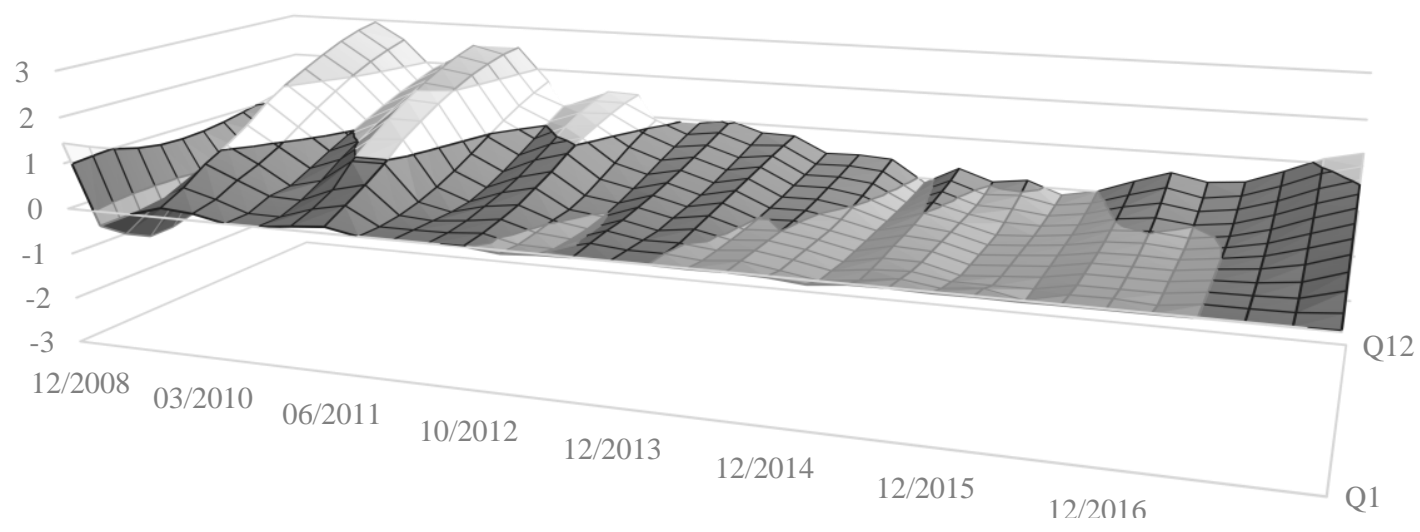

(3c) Change in the three-month EURIBOR rate implied by the Eurozone swap curve (1=100bp)

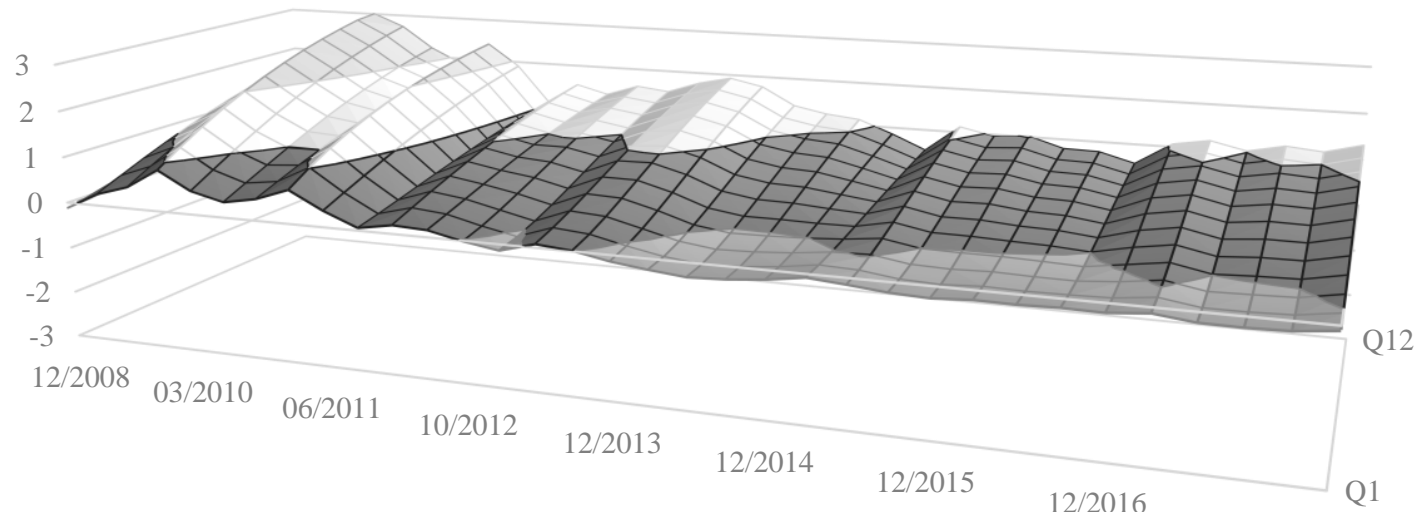

Source: Author's calculations.

Note: The chart presents the expected change in interest rates in forthcoming quarters during the period of 2008-2018. The x-axis presents the timeframe. The y-axis presents the forecast horizon (Q1 = next quarter, Q12 = end of forecast horizon). Finally, the z-axis is the number of basis points by which interest rates are expected to increase or decrease. The aim of the graph is to enable visualization of the similarity between market rate expectations in Norway (panel 1) and the Norges Bank projection (panel 2) or the expectations in the Eurozone (panel 3).

The changes in the three-month market rates were calculated using the Nelson-Siegel model. See the methodology section for further information. The EURIBOR chart uses data corresponding to the monetary policy report publication date. Its shape will be different for every central bank. 
Figure 4: Predictive accuracy of expected change in the NIBOR three-month rate-comparison between central bank projection and the EURIBOR3M expectations

(a) RMSE (2009-2018)

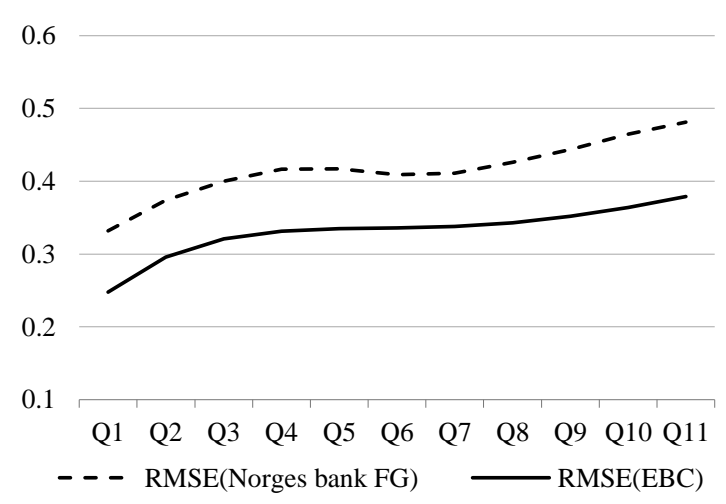

(b) RMSE (2012-2018)

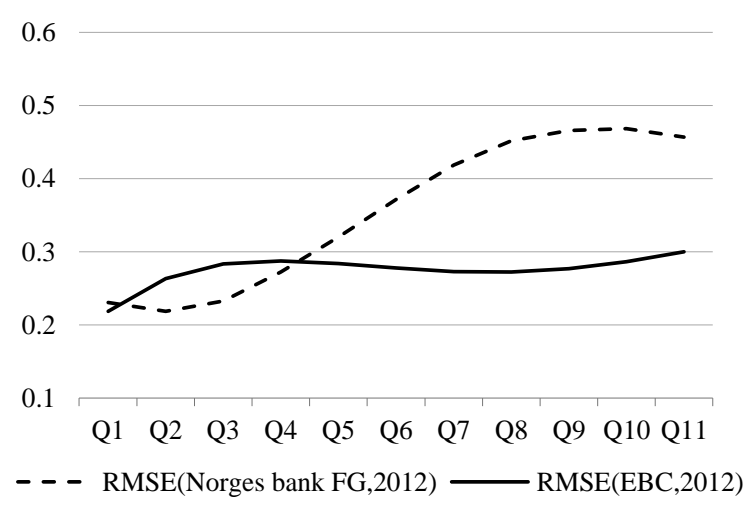

Source: Author's calculations.

Note: The dotted line denotes root mean square error statistics for central bank projections, calculated with formula (5). Error is defined as the difference between expected change on the three-month rate in Norway and forecasted change in policy rate in the Norges Bank projections. The solid line describes similarly defined statistics, where error is defined as the difference between expected short-term rate increases in Norway and the Eurozone (EURIBOR 3M). Q1, Q2, .. denote the next forecast horizons; see the methodology section for further information.

Figure 5: Implied change in the three-month PRIBOR, three-month EURIBOR, and change in policy rate in the CNB projection

(5a) Change in the three-month PRIBOR rate implied by the Czechia swap curve (1 denotes 100 basis points; further bp)

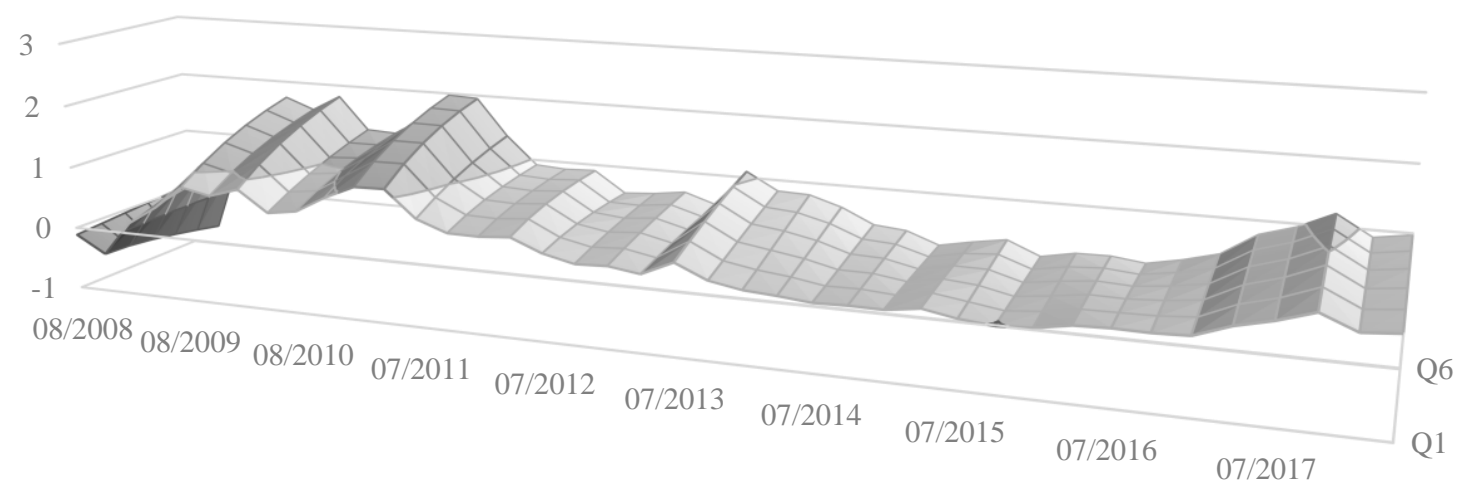

Continued on the next page 
Figure 5: Implied change in the three-month PRIBOR, three-month EURIBOR, and change in policy rate in the CNB projection (Continued)

(5b) Change in policy rate in the CNB projection ( $1=100 \mathrm{bp})$

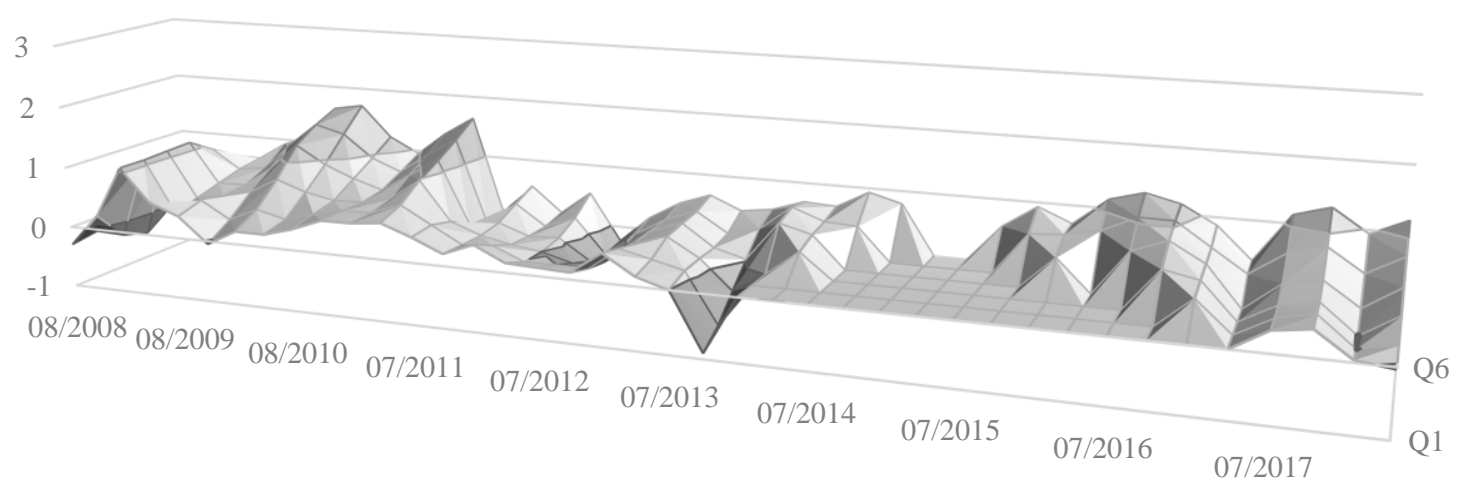

(5c) Change in the three-month EURIBOR rate implied by the eurozone swap curve ( $1=100 \mathrm{bp})$

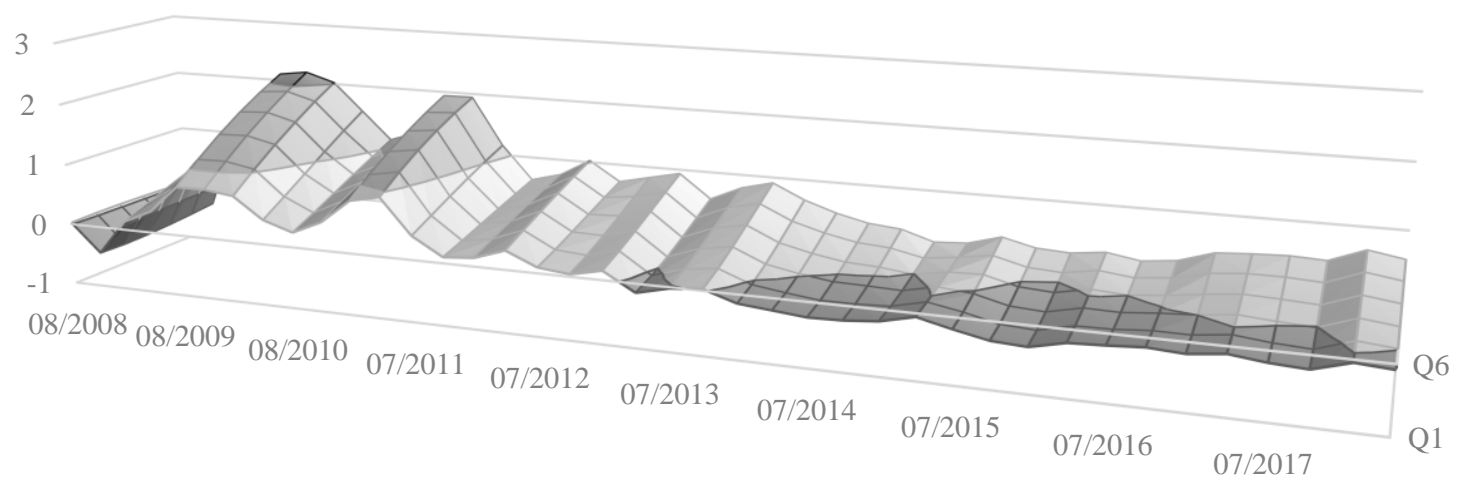

Source: Author's calculations.

Note: The chart presents the expected changes in interest rates in forthcoming quarters during the period of 2008-2018. The $\mathrm{x}$-axis presents the timeframe. The $\mathrm{y}$-axis presents the forecast horizon $(\mathrm{Q} 1=$ next quarter, $\mathrm{Q} 6=$ end of forecast horizon). Finally, the z-axis is the number of basis points by which interest rates are expected to increase or decrease. The aim of the graph is to enable visualization of the similarity between market rate expectations in Czechia (panel 1) and the CNB bank projection (panel 2) or the expectations in the Eurozone (panel 3).

The changes in the three-month market rates were calculated using the Nelson-Siegel model. See the methodology section for further information. The EURIBOR chart uses data corresponding to the monetary policy report publication date. Its shape will be different for every central bank. 
Figure 6: Predictive accuracy of expected change in the PRIBOR three-month ratecomparison between central bank projection and the EURIBOR3M expectations

(a) RMSE (2010-2018)

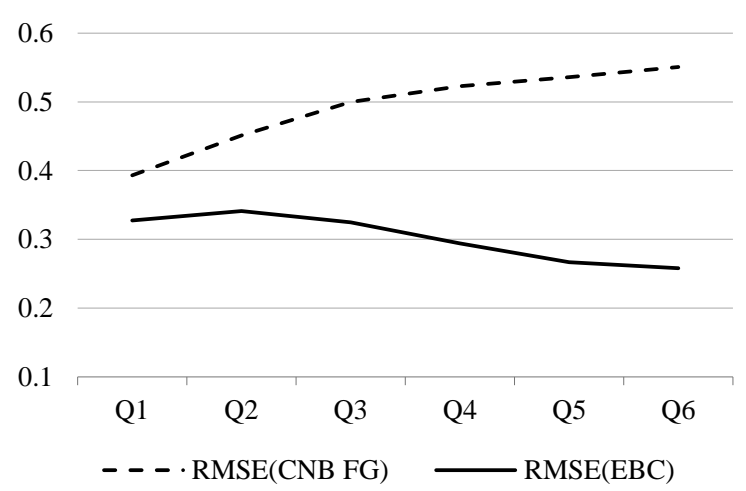

(b) RMSE (2012-2018)

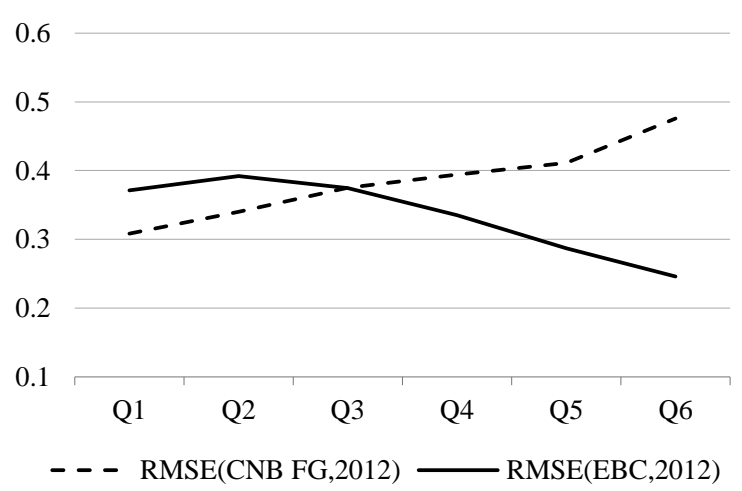

Source: Author's calculations.

Note: The dotted line denotes root mean square error statistics for central bank projections, calculated with formula (5). Error is defined as the difference between expected change in the three-month rate in Czechia and forecasted change in policy rate in CNB projections. The solid line describes similarly defined statistics, where error is defined as the difference between expected short-term rate increases in Czechia and the Eurozone (EURIBOR 3M). Q1, Q2, ... denote the next forecast horizons; see the methodology page for further information.

Table 1: Sweden - RMSE

\begin{tabular}{lcccccccccccc}
\hline & Q1 & Q2 & Q3 & Q4 & Q5 & Q6 & Q7 & Q8 & Q9 & Q10 & Q11 & Q12 \\
\hline \multicolumn{10}{c}{ Timeframe: } & $\mathbf{2 0 0 7 . 0 2}$ & $\mathbf{2 0 1 8 . 6}$ \\
\hline Riksbank projection & 0.37 & 0.42 & 0.48 & 0.54 & 0.57 & 0.58 & 0.56 & 0.55 & 0.56 & 0.59 & 0.65 & $\#$ N/A \\
ECB pol. expectations & 0.22 & 0.28 & 0.32 & 0.35 & 0.39 & 0.42 & 0.45 & 0.48 & 0.50 & 0.53 & 0.56 & 0.58 \\
\hline
\end{tabular}

Timeframe: 2012.10 - 2018.6

\begin{tabular}{lllllllllllll}
\hline Riksbank projection & 0.14 & 0.16 & 0.23 & 0.30 & 0.33 & 0.33 & 0.33 & 0.35 & 0.38 & 0.42 & 0.46 & $\# \mathrm{~N} / \mathrm{A}$ \\
ECB pol. expectations & 0.11 & 0.14 & 0.17 & 0.20 & 0.23 & 0.25 & 0.28 & 0.31 & 0.34 & 0.36 & 0.39 & 0.41 \\
\hline
\end{tabular}

Source: Author's calculations.

Note: The table presents detailed data used to create Figure 2. See figure footnote for further information. 
Table 2: Results of Mariano-Diebold test for Sweden-comparison of predictive accuracy between change in central bank projection and the EURIBOR expectations

\begin{tabular}{|c|c|c|c|c|c|c|c|c|c|c|c|}
\hline & Q1 & Q2 & Q3 & Q4 & Q5 & Q6 & Q7 & Q8 & Q9 & Q10 & Q11 \\
\hline \multicolumn{12}{|c|}{ Timeframe: $2007.02-2018.6$} \\
\hline Diebold-Mariano test statistic & 3.17 & 1.39 & 1.02 & 0.95 & 0.91 & 0.82 & 0.73 & 0.67 & 0.83 & 1.86 & 2.20 \\
\hline P-value: Two-sided test & 0.00 & 0.17 & 0.31 & 0.35 & 0.37 & 0.42 & 0.47 & 0.51 & 0.41 & 0.07 & 0.03 \\
\hline $\begin{array}{l}\text { P-value: One-sided test - } \\
\text { alternative ECB less accurate }\end{array}$ & 0.90 & 0.63 & 0.75 & 0.85 & 0.94 & 0.99 & 0.95 & 0.94 & 1.00 & 1.00 & 1.00 \\
\hline $\begin{array}{l}\text { P-value: One-sided test - } \\
\text { alternative ECB more accurate }\end{array}$ & 0.00 & 0.09 & 0.16 & 0.17 & 0.18 & 0.21 & 0.24 & 0.25 & 0.21 & 0.03 & 0.02 \\
\hline \multicolumn{12}{|c|}{ Timeframe: $2012.10-2018.6$} \\
\hline Diebold-Mariano test statistic & 1.30 & 0.34 & 0.69 & 1.06 & 1.58 & 2.68 & 1.67 & 1.57 & 2.79 & 4.80 & 4.23 \\
\hline P-value: Two-sided test & 0.21 & 0.73 & 0.50 & 0.30 & 0.13 & 0.01 & 0.11 & 0.13 & 0.01 & 0.00 & 0.00 \\
\hline $\begin{array}{l}\text { P-value: One-sided test - } \\
\text { alternative ECB less accurate }\end{array}$ & 0.90 & 0.63 & 0.75 & 0.85 & 0.94 & 0.99 & 0.95 & 0.94 & 1.00 & 1.00 & 1.00 \\
\hline $\begin{array}{l}\text { P-value: One-sided test - } \\
\text { alternative ECB more accurate }\end{array}$ & 0.10 & 0.37 & 0.25 & 0.15 & 0.06 & 0.01 & 0.05 & 0.06 & 0.00 & 0.00 & 0.00 \\
\hline
\end{tabular}

Source: Author's calculations.

Note: The test hypothesis assumes equal accuracy of both the Riksbank projection and ECB expectations. The alternative hypothesis in the two-sided test assumes a different forecasting performance. The one-sided test explicitly indicates which projections are statistically less/more accurate. 
Table 3: Norway - RMSE

\begin{tabular}{lcccccccccccc}
\hline & Q1 & Q2 & Q3 & Q4 & Q5 & Q6 & Q7 & Q8 & Q9 & Q10 & Q11 & Q12 \\
\hline \multicolumn{10}{c}{ Timeframe: } & 2009.03 - 2018.6 \\
\hline Norges Bank projection & 0.33 & 0.37 & 0.40 & 0.42 & 0.42 & 0.41 & 0.41 & 0.43 & 0.44 & 0.46 & 0.48 & \#N/A \\
ECB pol. expectations & 0.25 & 0.30 & 0.32 & 0.33 & 0.33 & 0.34 & 0.34 & 0.34 & 0.35 & 0.36 & 0.38 & 0.40 \\
\hline
\end{tabular}

Timeframe: $2012.10-2018.6$

\begin{tabular}{llllllllllllc}
\hline Norges Bank projection & 0.23 & 0.22 & 0.23 & 0.27 & 0.32 & 0.37 & 0.42 & 0.45 & 0.47 & 0.47 & 0.46 & $\# \mathrm{~N} / \mathrm{A}$ \\
ECB pol. expectations & 0.22 & 0.26 & 0.28 & 0.29 & 0.28 & 0.28 & 0.27 & 0.27 & 0.28 & 0.29 & 0.30 & 0.32 \\
\hline
\end{tabular}

Source: Author's calculations.

Note: The table presents detailed data used to create Figure 4. See figure footnote for further information.

Table 4: Results of the Mariano-Diebold test for Norway-comparison of predictive accuracy between change in central bank projection and the EURIBOR expectations.

\begin{tabular}{|c|c|c|c|c|c|c|c|c|c|c|c|}
\hline & Q1 & Q2 & Q3 & Q4 & Q5 & Q6 & Q7 & Q8 & Q9 & Q10 & Q11 \\
\hline \multicolumn{12}{|c|}{ Timeframe: 2009.03 - 2018.6} \\
\hline Diebold-Mariano test statistic & 1.18 & 0.763 & 1.03 & 1.11 & 1.32 & 1.26 & 0.881 & 0.866 & 0.99 & 1.13 & 1.43 \\
\hline P-value: Two-sided test & 0.25 & 0.45 & 0.31 & 0.28 & 0.20 & 0.22 & 0.39 & 0.39 & 0.33 & 0.27 & 0.16 \\
\hline $\begin{array}{l}\text { P-value: One-sided test - } \\
\text { alternative ECB less accurate }\end{array}$ & 0.88 & 0.77 & 0.84 & 0.86 & 0.90 & 0.89 & 0.81 & 0.80 & 0.84 & 0.87 & 0.92 \\
\hline $\begin{array}{l}\text { P-value: One-sided test - } \\
\text { alternative ECB more accurate }\end{array}$ & 0.12 & 0.23 & 0.16 & 0.14 & 0.10 & 0.11 & 0.19 & 0.20 & 0.17 & 0.13 & 0.08 \\
\hline \multicolumn{12}{|c|}{ Timeframe: 2012.10 - 2018.6} \\
\hline Diebold-Mariano test statistic & 0.36 & -1.43 & -1.09 & -0.16 & 0.34 & 0.85 & 1.69 & 2.60 & 3.85 & 2.50 & 2.26 \\
\hline P-value: Two-sided test & 0.72 & 0.17 & 0.29 & 0.88 & 0.74 & 0.41 & 0.11 & 0.02 & 0.00 & 0.02 & 0.03 \\
\hline $\begin{array}{l}\text { P-value: One-sided test - } \\
\text { alternative ECB less accurate }\end{array}$ & 0.64 & 0.08 & 0.14 & 0.44 & 0.63 & 0.80 & 0.95 & 0.99 & 1.00 & 0.99 & 0.98 \\
\hline $\begin{array}{l}\text { P-value: One-sided test - } \\
\text { alternative ECB more accurate }\end{array}$ & 0.36 & 0.92 & 0.86 & 0.56 & 0.37 & 0.20 & 0.05 & 0.01 & 0.00 & 0.01 & 0.02 \\
\hline
\end{tabular}

Source: Author's calculations.

Note: Detailed information about the test construction is provided in Table 2. 
Table 5: Czechia - RMSE calculations

\begin{tabular}{|c|c|c|c|c|c|c|c|c|c|c|c|c|}
\hline & Q1 & Q2 & Q3 & Q4 & Q5 & Q6 & Q7 & Q8 & Q9 & Q10 & Q11 & Q12 \\
\hline \multicolumn{13}{|c|}{ Timeframe: $2008.10-2018.6$} \\
\hline CNB projection & 0.39 & 0.45 & 0.50 & 0.52 & 0.54 & 0.55 & $\# \mathrm{~N} / \mathrm{A}$ & $\# \mathrm{~N} / \mathrm{A}$ & $\# \mathrm{~N} / \mathrm{A}$ & $\# \mathrm{~N} / \mathrm{A}$ & $\# \mathrm{~N} / \mathrm{A}$ & $\# \mathrm{~N} / \mathrm{A}$ \\
\hline $\begin{array}{c}\text { ECB pol. } \\
\text { expectations }\end{array}$ & 0.33 & 0.34 & 0.32 & 0.29 & 0.27 & 0.26 & 0.28 & 0.32 & 0.37 & 0.43 & 0.49 & 0.55 \\
\hline \multicolumn{13}{|c|}{ Timeframe: $2012.10-2018.6$} \\
\hline CNB projection & 0.31 & 0.34 & 0.38 & 0.39 & 0.41 & 0.48 & $\# \mathrm{~N} / \mathrm{A}$ & $\# \mathrm{~N} / \mathrm{A}$ & $\# \mathrm{~N} / \mathrm{A}$ & $\# \mathrm{~N} / \mathrm{A}$ & $\# \mathrm{~N} / \mathrm{A}$ & $\# \mathrm{~N} / \mathrm{A}$ \\
\hline $\begin{array}{l}\text { ECB pol. } \\
\text { expectations }\end{array}$ & 0.37 & 0.39 & 0.37 & 0.34 & 0.29 & 0.25 & 0.23 & 0.24 & 0.28 & 0.33 & 0.39 & 0.45 \\
\hline
\end{tabular}

Source: Author's calculations.

Note: The table presents detailed data used to create Figure 2. See figure footnote for further information.

Table 6: Results of the Mariano-Diebold test for Czechia-comparison of predictive accuracy between change in central bank projection and the EURIBOR expectations.

\begin{tabular}{lcccccc}
\hline & Q1 & Q2 & Q3 & Q4 & Q5 & Q6 \\
\hline & Timeframe: 2008.10 & $\mathbf{2 0 1 8 . 6}$ & & & & \\
\hline Diebold-Mariano test statistic & 0.97 & 1.40 & 1.99 & 2.20 & 2.23 & 3.11 \\
P-value: Two-sided test & 0.34 & 0.17 & 0.05 & 0.03 & 0.03 & 0.00 \\
P-value: One-sided test - alternative ECB less accurate & 0.83 & 0.92 & 0.97 & 0.98 & 0.98 & 1.00 \\
P-value: One-sided test - alternative ECB more accurate & 0.17 & 0.08 & 0.03 & 0.02 & 0.02 & 0.00 \\
\hline
\end{tabular}

Timeframe: 2012.10 - 2018.6

Diebold-Mariano test statistic

$\begin{array}{cccccc}-0.67 & -0.58 & 0.01 & 0.71 & 0.85 & 1.36 \\ 0.51 & 0.57 & 0.99 & 0.49 & 0.40 & 0.19 \\ 0.26 & 0.29 & 0.50 & 0.76 & 0.80 & 0.91 \\ 0.74 & 0.71 & 0.50 & 0.24 & 0.20 & 0.09\end{array}$

Source: Author's calculations.

Note: Detailed information about the test construction is provided in Table 2 . 